\title{
Multiple sclerosis in sibling pairs: an analysis of 250 families
}

\author{
J Chataway, A Mander, N Robertson, S Sawcer, J Deans, M Fraser, S Broadley, \\ D Clayton, A Compston
}

University of

Cambridge Neurology unit, Addenbrooke's Hospital, Hills Road, Cambridge, CB2 2QQ, UK

J Chataway

N Robertson

S Sawcer

J Deans

M Fraser

$S$ Broadley

A Compston

MRC Biostatistics

Unit, Institute of

Public Health,

University Forvie Site,

Robinson Way,

Cambridge, CB2 2SR,

UK

A Mander

D Clayton

University

Department of

Neurology, University

Hospital of Wales,

Heath Park, Cardiff,

CF4 4XN, UK

$\mathrm{N}$ Robertson

ED Adrian Building, University Forvie Site, Robinson Way, Cambridge, CB2 2SR, UK

A Compston

Correspondence to: Dr A Compston

alastair.compston medschl.cam.ac.uk

Received 19 January 2001 and in revised form

16 July 2001

Accepted 20 July 2001

\begin{abstract}
Objectives-To assess the potential contribution of genetic factors to clinical phenotype in multiple sclerosis.

Methods-Using a cohort of 262 pairs of coaffected siblings from 250 families with multiple sclerosis, intersibling concordance analysis was used to explore underlying genetic mechanisms in disease pathogenesis by assessing parameters of disease course, clinical presentation, age and year of onset, and measures of disability and handicap.

Results-Adjusted intraclass correlation coefficients were not significant for either age of onset or for year of first symptom. One third of sibling pairs were concordant for presenting symptom (81/262), a result that was non-significant. However, course type was identical in $50 \%$ of the sibling pairs $(\kappa=0.17 \quad(95 \%$ confidence interval (95\% CI) 0.08 to 0.26$)$ ) indicating a significant result. Severity of the disease at assessment, using the Kurtzke and CAMBS scales, demonstrated that whereas there was no agreement for relapse rate in the previous year within the sibship, there was significant concordance for measures of disability $(\kappa=0.11$ $(95 \%$ CI 0.04 to 0.19$))$, progression $(\kappa=0.09$ $(95 \% \mathrm{CI} 0.01$ to 0.18$)$ ) and handicap ( $\kappa=0.08(95 \%$ CI 0.02 to 0.14$)$ ).

Conclusions-Within a sibship, the clinical presentation tends to be different. However, once established, concordance is more likely to be seen for the ultimate course, leading in the end to similar disability and handicap scores. These results are consistent with the hypothesis that genes influence both disease susceptibility and evolution in multiple sclerosis. (F Neurol Neurosurg Psychiatry 2001;71:757-761)
\end{abstract}

Keywords: multiple sclerosis; sibling pair; concordance

The familial tendency of multiple sclerosis is well recognised with relative risks of 100-190 for identical twins ${ }^{12} ; 7-13$ for half ${ }^{3}$ and full siblings ${ }^{4}$; and 5.5 for the offspring of single affected, ${ }^{4}$ and 60 for conjugal parents. ${ }^{5}$. Coaffected siblings can be used as a resource for identifying susceptibility genes and have formed the basis for genome screens in various diseases through linkage analysis including insulin dependent diabetes, ${ }^{6}$ asthma, ${ }^{7}$ and inflammatory bowel disease. ${ }^{8}$ Three original genome screens were carried out in multiple sclerosis, ${ }^{9-11}$ with an additional one from a smaller genetically isolated Finnish population. ${ }^{12}$ Current approaches include attempts to identify susceptibility genes within these regions of interest using the positional candidate approach - now accelerated by the first draft of the human genome map; further full genome linkage screens with the aim of meta-analysis; and full linkage disequilibrium genome screening using case-control and family based association methods. Together these reinforce the role of the HLA region ${ }^{13}{ }^{14}$; they identify areas of genetic overlap between populations; and document large exclusion zones which encompass $95 \%$ of the genome for genes of large effect and $65 \%$ for genes of moderate effect.

Sibling pairs also provide an opportunity for examining clinical phenotypic heterogeneity within kindreds; and for determining the relative contribution of genetic and environmental forces in shaping the disease expression. The first set from the United Kingdom coaffected sibling pair cohort has already been described numbering 166 families and contributing 177 sibling pairs. ${ }^{15}$ This series is now extended with reanalysis of the cumulative total of 262 pairs, primarily using a $\kappa$ function which is able to incorporate potentially confounding variables and generate 95\% confidence intervals (95\% CIs) for the results obtained, through a novel bootstrap simulation process.

\section{Methods}

SIBLING RECRUITMENT

As part of an ongoing study of the genetic epidemiology of multiple sclerosis notifications were received from members of the Association of British Neurologists, with limited recruitment also occurring through articles distributed by the Multiple Sclerosis Society.

Patients were contacted by either a neurology research registrar or experienced neurology research sister, and the project explained. If the family was interested in taking part, arrangements were made to visit the proband at home; a standard history and examination were performed, $30 \mathrm{ml}$ of blood drawn for extraction of DNA and subsequent genetic analysis, and arrangements made for the full medical notes to be obtained from the supervising clinician. A newsletter was distributed to all those involved in the project to keep them up to date with general progress of the research. Ethical approval was obtained from the local research ethics committee and multicentre research ethics committee.

DEFINITION

Case definition followed the Poser criteria ${ }^{16}$ with each sibling pair including at least one 
member who was clinically definite (grade A), and the other either laboratory supported (B) or clinically probable (C). Efforts were made to exclude possible phenocopies such as the hereditary parapareses and ataxias. In addition, the entire cohort was screened for the autosomal dominant spinocerebellar ataxia (SCA) triplet expansion mutations, ${ }^{17}$ all male-male pairs tested for the presence of adrenoleukodystrophy (by assaying fasting concentrations of very long chain fatty acids), and more recently a random sample for mutations in the CADASIL gene. No examples of these disorders were identified.

Sibling 1 was designated as the member who first exhibited symptoms rather than the oldest or the first diagnosed sibling. ${ }^{15}$ Although guided by the patient's own recall in assigning clinical onset of disease, meticulous attention was placed on clinical assessment during the visit, where a full history and examination were taken, supplemented by copies of the case notes. In this way a complete description of the disease presentation and progression was built up. Where there was potential inaccuracy due to cognitive impairment, then the documentary evidence was complemented by discussions with the relevant clinician.

Disease course and character were described in accordance with the European Database for Multiple Sclerosis (EDMUS) protocol,${ }^{18}$ with four categories being defined: relapse-remitting $(\mathrm{RR})$, primary progressive $(\mathrm{P})$, secondary progressive (RR-P), and unknown (U). An attempt was made to assign symptoms to one or more neuroanatomical locations. Bilateral limb dysfunction and sphincter involvement were scored as cord disease; unilateral limb dysfunction alone as cortical disease; ataxia/dysarthria with or without cranial nerve/limb dysfunction as brainstem/cerebellar disease (no attempt was made to distinguish these two); whereas optic nerve and cognitive dysfunction were generally unambiguous. Despite limitations, this represents an attempt to demarcate the anatomical syndromes of multiple sclerosis. Disease severity was graded according to the Kurtzke expanded disability status scale $(\text { EDSS })^{19}$ and CAMBS. ${ }^{20}$

In the $5 \%$ of families with trios affected, three possible pairs $\mathrm{AB}, \mathrm{AC}$, and $\mathrm{BC}$, were weighted as two thirds so that each family contributed two pairs to the analysis.

\section{STATISTICAL TECHNIQUES}

Kappa and intraclass correlation coefficient were used to measure pairwise concordance. The first was used for categorical data and the second for continuous data. These were initially developed for measuring agreement between raters, but their application in sibling pair analysis was suggested by Fleiss. ${ }^{21}$ Application to multiplex sibships substituted pairs of siblings as pairs of raters. Our analysis assessed whether sibling pairs were more alike than a random pair sampled from the group. Statistics close to 1 indicated that sibling pairs were extremely alike and values of 0 indicated that the sibling pairs were no different from any random pair generated from within the cohort.
Any variable could have been tested for this type of concordance between siblings. We used: sibling sex, disease course, presenting symptoms, and site, Kurtzke and CAMBS disability/ handicap scales, and age/year of onset, with statistics reported as the point estimate with the corresponding 95\% CIs. The bootstrap $\mathrm{CIs}^{22}$ were not symmetric about the point estimate; therefore the construction of approximate CIs under the normal distribution would have been wrong. Results were considered significant at the $5 \%$ level if the interval did not contain 0 .

As previously noted by Robertson et al, various confounding relations may be present in analysing clinical features of sibling pairs ${ }^{15}$; however only univariate adjustment was required as the confounders had minimal effect on the data. Therefore, more complex multiple variable adjustments were not performed, and the interpretation of results specifically itemises only the unadjusted data. Adjustment for sibling sex could not be made in most cases because the $\kappa$ function became undefinable due to the many rare cells in the cross tabulation of outcome and sibling sex. For those situations where adjustment for sex could be made, there was no alteration in the original results; sibling sex was therefore excluded from the list of possible adjustors. Our analysis includes adjusted values for the intraclass correlation coefficient and the $\kappa$ statistic $^{23}$ for variables including duration, year of birth, age of first symptoms, and year of first symptoms.

\section{Results}

RECRUITMENT

The register of familial multiple sclerosis had received 1013 referrals at the time of this study, of which 456 were affected sibling pairs. 152 were excluded before the visit because of: duplicate referrals (14), not a sibling pair (five), untraceable siblings (19), cosibling dead (48), geographical inaccessibility (11), participation refused (17), medical staff did not recommend contact (seven), monophasic disease (15), and not multiple sclerosis (16). The attrition rate after the visit was $54 / 304 \quad(18 \%$ families visited), with further exclusions due to nonpaternity (seven), only one sibling ultimately available (nine), monophasic disease (16), not multiple sclerosis (two), inadequate clinical documentation (10), and possible progressive spastic paraparesis or spinocerebellar ataxia (10).

\section{DEMOGRAPHY}

Table 1 details the characteristics of this cohort in terms of pedigree structure and sex. The total number of pedigrees was $250-238$ pairs and 12 trios-equating to an effective number

Table 1 Cohort structure

\begin{tabular}{llll}
\hline Sex & Pairs & $\begin{array}{l}\text { Pairs from } \\
\text { trios }\end{array}$ & Effective total \\
\hline FF & 115 & 12 & 127 \\
MM & 21 & 2.7 & 23.7 \\
MF & 102 & 9.3 & 111.3 \\
All & 238 & 24 & 262
\end{tabular}

^Trios weighted as $2 / 3$. 
Table 2 Pairwise concordance for all variables and confounders

\begin{tabular}{|c|c|c|c|c|c|}
\hline Confounder & No confounder & Duration & Year of birth & Age of first symptom & Year of first symptom \\
\hline Sex & $0.02(-0.09$ to 0.13$)$ & $0.01(-0.08$ to 0.13$)$ & $0.02(-0.09$ to 0.13$)$ & $0.02(-0.08$ to 0.13$)$ & $0.02(-0.08$ to 0.12$)$ \\
\hline Disease course & $0.17(0.08 \text { to } 0.26)^{\star}$ & $0.16(0.07 \text { to } 0.24)^{\star}$ & $0.15(0.07 \text { to } 0.26)^{\star}$ & $0.16(0.07 \text { to } 0.24)^{\star}$ & $0.16(0.08 \text { to } 0.25)^{\star}$ \\
\hline Dichotomised disease course & $0.09(-0.01$ to 0.22$)$ & $0.09(-0.01$ to 0.23$)$ & $0.07(-0.03$ to 0.19$)$ & $0.08(-0.03$ to 0.20$)$ & $0.09(-0.01$ to 0.23$)$ \\
\hline Presenting symptoms & $0.02(-0.07$ to 0.15$)$ & $0.03(-0.08$ to 0.13$)$ & $0.02(-0.08$ to 0.13$)$ & $0.03(-0.09$ to 0.14$)$ & $0.02(-0.08$ to 0.12$)$ \\
\hline Limb motor $v$ others & $0.09(-0.02$ to 0.21$)$ & $0.09(-0.02$ to 0.20$)$ & $0.09(-0.02$ to 0.21$)$ & $0.08(-0.02$ to 0.21$)$ & $0.09(-0.03$ to 0.21$)$ \\
\hline Limb sensory $v$ others & $0.04(-0.01$ to 0.10$)$ & $0.04(-0.02$ to 0.10$)$ & $0.04(-0.01$ to 0.11$)$ & $0.04(-0.02$ to 0.10$)$ & $0.04(-0.02$ to 0.09$)$ \\
\hline Primary presenting site & $0.05(-0.01$ to 0.12$)$ & $0.05(-0.01$ to 0.12$)$ & $0.05(-0.01$ to 0.12$)$ & $0.05(-0.02$ to 0.12$)$ & $0.05(-0.01$ to 0.12$)$ \\
\hline Kurtzke disability score & $0.06(0.02 \text { to } 0.11)^{\star}$ & $0.05(0.02 \text { to } 0.11)^{\star}$ & $0.06(0.01 \text { to } 0.10)^{\star}$ & $0.06(0.02 \text { to } 0.11)^{\star}$ & $0.05(0.02 \text { to } 0.10)^{\star}$ \\
\hline CAMBS-D & $0.11(0.04 \text { to } 0.19)^{\star}$ & $0.10(0.03 \text { to } 0.18)^{\star}$ & $0.09(0.02 \text { to } 0.17)^{\star}$ & $0.11(0.05 \text { to } 0.20)^{\star}$ & $0.10(0.03 \text { to } 0.18)^{\star}$ \\
\hline CAMBS-R & $0.05(-0.02$ to 0.16$)$ & $0.05(-0.03$ to 0.16$)$ & $0.05(-0.03$ to 0.16$)$ & $0.05(-0.03$ to 0.16$)$ & $0.05(-0.03$ to 0.15$)$ \\
\hline CAMBS-P & $0.09(0.01 \text { to } 0.18)^{\star}$ & $0.09(0.01 \text { to } 0.18)^{\star}$ & $0.09(0.01 \text { to } 0.18)^{\star}$ & $0.09(0.01 \text { to } 0.18)^{\star}$ & $0.09(0.02 \text { to } 0.20)^{\star}$ \\
\hline CAMBS-H & $0.08(0.02 \text { to } 0.14)^{\star}$ & $0.08(0.02 \text { to } 0.14)^{\star}$ & $0.07(0.01 \text { to } 0.13)^{\star}$ & $0.08(0.02 \text { to } 0.15)^{\star}$ & $0.08(0.02 \text { to } 0.15)^{\star}$ \\
\hline
\end{tabular}

Results in parentheses are $95 \%$ CIs

*Indicates a significant result ( $95 \%$ CIs do not include 0$)$.

of 262 sibling pairs, an increase of 85 from the previous report. The sex structure of like and unlike sex pairings matches other series, including population based cohorts in that $359 / 512$ people were female $(70 \%)$.

\section{CONCORDANCE ANALYSIS}

A total of 395 patients were Poser grade A, 37 grade $\mathrm{B}$, and 80 grade $\mathrm{C}$. (The three with previously described grade $\mathrm{D}$ disease were reevaluated during the study period and their Poser ratings had increased to A.) As expected, there was no agreement within sibships on the degree of diagnostic certainty, as this was influenced by the use of laboratory investigations, which would have been relatively unavailable to the older siblings, and by disease duration which disadvantages clinical status in the second affected.

Table 2 outlines the results which are broken down into the following categories

Disease course

Identical course type was found in $50 \%$ of the sibling pairs if RR and RR-P were considered as separate groups (table $3 ; \kappa=0.17$ (95\% CI 0.08 to 0.26$)$ ). If the categories are dichotomised into RR/RR-P ( $\left.R^{\star}\right)$ and $\mathrm{P}$ alone, the confidence intervals widened and the result was no longer significant $(\kappa=0.09$ (95\% CI -0.01 to 0.22$)$ ).

\section{Presenting symptoms and signs}

The presenting symptoms are summarised in table 4. One third of sibling pairs were concordant for presenting symptom (81/262; not significant, $\kappa=0.02(95 \%$ CI -0.07 to $0.15)$ ). Dichotomising the data to limb motor or long tract sensory versus remaining symptoms was also non-significant $(\kappa=0.09(95 \%$ $\mathrm{CI}-0.02$ to 0.21$)$ ) and $0.04(95 \% \mathrm{CI}-0.02$ to $0.10)$ ) respectively). There was no significant concordance either for the main presenting site (73/262; $\kappa=0.05$ (95\% CI -0.01 to 0.12 ; table $5)$.

\section{Disability}

Severity of the disease at assessment using the Kurtzke and CAMBS scales demonstrated that whereas there was no similarity of relapse rate in the previous year within sibships, there was significant concordance for measures of disability, progression, and handicap, which remained significant after adjustment.
Age and year of onset

Intraclass correlation coefficients of 0.23 for age of onset and 0.40 for year of first symptom were significant but to a large extent reflected the method of sibling sampling, as previously described in the original cohort analysis (15). Adjusted values were not significant for either parameter ( $\mathrm{p} \sim 0.06$ ). The median time to diagnosis for the first sibling was 3 years (maximum 31 years, interquartile range $1-10$ years), with the second sibling having a median of 4 years (maximum 38 years, interquartile range 2-10 years).

Table 3 Disease course within sibships

\begin{tabular}{llll}
\hline Disease course & Frequency & $\begin{array}{l}\text { Dichotomised } \\
\text { disease course }\end{array}$ & Frequency \\
\hline $\mathrm{RR} v \mathrm{RR}$ & 84 & & \\
$\mathrm{RR} v \mathrm{RR}-\mathrm{P}$ & 68.3 & $\mathrm{RR}^{\star} v \mathrm{RR}^{\star}$ & 191.7 \\
$\mathrm{RR} v \mathrm{P}$ & 33.7 & $\mathrm{RR}^{\star} v \mathrm{P}$ & 60.7 \\
$\mathrm{RR}-\mathrm{P} v \mathrm{RR}-\mathrm{P}$ & 39.3 & $\mathrm{P} v \mathrm{P}$ & 9.7 \\
$\mathrm{RR}-\mathrm{P} v \mathrm{P}$ & 27 & & \\
$\mathrm{P} v \mathrm{P}$ & 9.7 & & \\
\hline
\end{tabular}

$\mathrm{RR}=$ Relapsing-remitting; $\mathrm{P}=$ primary progressive; $\mathrm{RR}-\mathrm{P}=$ secondary progressive.

Table 4 Symptom presentation

\begin{tabular}{llll}
\hline & $\begin{array}{l}\text { Number of } \\
\text { patients } \\
(n=524)\end{array}$ & $\begin{array}{l}\text { Frequency } \\
(\%)\end{array}$ & $\begin{array}{l}\text { Sibling pairs } \\
\text { concordant }\end{array}$ \\
\hline Presenting symptoms & 174 & 33 & 32 \\
Lower limb dysfunction & 17 & 3 & 4 \\
Upper limb dysfunction & 17 & 25 & 28 \\
Long tract sensory & 131 & 0.7 & 2 \\
Sphincter dysfunction & 4 & 0.2 & 0 \\
Sexual dysfunction & 1 & 1.4 & 0 \\
Facial motor weakness & 8 & 3 & 2 \\
Facial sensory weakness & 15 & 7 & 3 \\
Oculomotor & 35 & 5 & 1 \\
Vestibular dysfunction & 27 & 0 & 0 \\
Bulbar dysfunction & 0 & 19 & 7 \\
Visual symptoms & 98 & 0 & 0 \\
Psychiatric symptoms & 0 & 0 & 0 \\
Cognitive deterioration & 0 & 2 & 2 \\
Other & 10 & 0.7 & 0 \\
Unknown & 4 & & \\
\hline
\end{tabular}

Table 5 Neuroanatomical presentation

\begin{tabular}{llll}
\hline & $\begin{array}{l}\text { Number of } \\
\text { patients } \\
(n=524)\end{array}$ & $\begin{array}{l}\text { Frequency } \\
(\%)\end{array}$ & $\begin{array}{l}\text { Sibling pairs } \\
\text { concordant }\end{array}$ \\
\hline Presenting site & 165 & 31 & 28 \\
Spinal cord & 114 & 22 & 17 \\
Brain stem/cerebellum & 98 & 19 & 7 \\
Optic nerve & 116 & 22 & 21 \\
Cortex & 31 & 6 & 0 \\
Unable to classify & & & \\
\hline
\end{tabular}




\section{Discussion}

The use of sibling pairs in exploring features of multiple sclerosis dates from the $1930 \mathrm{~s}^{24}$ when four probable cases were identified from a pool of 444 siblings. The world literature on validated sibling pairs has gradually increased as has the range of analyses, culminating in 1996 with the publication of three genome screens which utilised a combined total of 599 pairs. ${ }^{9-11}$ Reviewing these published series indicates that various methods of ascertainment ranging from attempted total population coverage (Orkneys ${ }^{25}$ and $\mathrm{Canada}^{26}$ ) to national tertiary care referrals ${ }^{27}{ }^{28}$ have been used in both the clinically oriented and molecular genetic series.

Two main themes emerge from comparative phenotypic studies: the relative contribution of genetic versus environmental factors (whether there is intersibling clustering for age of onset or year of disease onset); and clinical concordance data, which can also be applied to counselling individual families.

Although mean difference in age of onset was lower than year at onset ( $1.4 v 4.7$ years) in the study of Schapira et al, the difference did not reach significance. ${ }^{29}$ When sibling pairs and sporadic cases were compared by Doolittle et $a l,{ }^{27}$ about double the number of sibling pairs had an age at onset within 5 years of each other compared with sporadic cases, whereas this effect was not found for year at onset: simple comparison of the mean age at onset and year at onset showed that both were similar $(\sim 6$ years), demonstrating potential pitfalls in this style of analysis. This was reinforced by the study of Bulman et $a l^{26}$ which again showed these parameters to be the same ( $\sim 3$ years); but when the more complex technique of intraclass correlation was used, significance was demonstrated for age at onset. Smaller studies of between seven ${ }^{30}$ and 22 pairs $^{31}$ reached no firm conclusions. Our previous series found no correlation for age at onset, but did detect a small difference in year at onset, possibly due to anticipation of symptoms by the second sibling. No significance differences in age or year of onset were found in either the most recent United States or French series. ${ }^{28} 32$

We found concordance within sibships for disease course and measures of progression, handicap, and disability using both the EDSS and CAMBS measures, but not for presenting symptom and site, or relapse pattern over the preceding year. Comparing these data with the initial set of 166 pairs, the enlarged group reinforces the previous conclusion concerning concordance for disease course, with $\mathrm{\kappa}$ coefficients of $\sim 0.17(95 \%$ CI $\sim 0.07$ to 0.25$)$ regardless of the confounders used; augments them with novel findings for progression and degree of handicap which were previously not measured; demonstrates the positive findings for two measures of disability; but finds that concordance is lost for sex $(95 \%$ CI -0.09 to $0.13)$, implying that those original results were false positives due to a smaller sample size. Our disability data support the most recent French cohort which, using the progression index (PI) defined as the ratio of EDSS to disease duration if the duration was more than 5 years, reported a significant concordance in 61 pairs $(r=0.234, \mathrm{p}=0.030) .^{28}$

Taken together these results show that, within a sibship, the presentation is more likely to be different than the same. However, once established, concordance is more likely to be seen for the ultimate course, culminating in similar disability and handicap scores. As the disease process becomes established, measures of disease outcome are more likely than not to equilibrate within a sibship. Perhaps this is the expression of the hidden rounds of inflammation, demyelination, and axonal loss, which although initiated in different regions of the neuraxis, subsequently display similar tempos of progression and coalesce with the same outcome in any two siblings.

We are grateful to all those affected with multiple sclerosis and their families for involvement in this research project. The assistance of both the national organisation and local branches of the Multiple Sclerosis Society of Great Britain and Northern Ireland is gratefully acknowledged, coupled with help from many members of the Association of British Neurologists, who identified pedigrees. This work was supported by the Wellcome Trust and the Multiple Sclerosis Society of Great Britain and Northern Ireland.

1 Sadovnick AD, Armstrong H, Rice GPA, et al. A poulation based study of multiple sclerosis in twins: updated. Ann Neurol 1993;33:281-5.

2 Mumford CJ, Wood NW, Kellar-Wood HF, et al. The British Isles survey of multiple sclerosis in twins. Neurology 1994;44:11-15.

3 Sadovnick AD, Ebers GC, Dyment DA, et al. Evidence for genetic basis of multiple sclerosis. Lancet 1996;347:1728-

4 Robertson NP, Fraser M, Deans J, et al. Age adjusted recurrence risks for relatives of patients with multiple sclerosis Brain 1996;119:449-55

5 Robertson NP, O'Riordan JI, Chataway J, et al. Offspring recurrence rates and clinical characteristics of conjugal multiple sclerosis. Lancet 1997;349:1587-90.

6 Davies JL, Kawaguchi Y, Bennett ST, et al. A genome-wide search for human type 1 diabetes susceptibility genes. Nature 1994;371:130-6.

7 Daniels SE, Bhattacharrya S, James A, et al. A genome-wide search for quantitative trait loci underlying asthma. Nature 1996;383:247-50

8 Satsangi J, Parkes M, Louis E, et al. Two stage genome-wide search in inflammatory bowel disease provides evidence for susceptibility loci on chromosomes 3, 7 and 12. Nat Genet 1996;14:199-202.

9 Sawcer SJ, Jones HB, Feakes R, et al. A genome screen in multiple sclerosis reveals susceptibility loci on chromosomes 6p21 and 17q22. Nat Genet 1996;13:464-8.

10 Ebers GC, Kukay K, Bulman DE, et al. A full genome search in multiple sclerosis. Nat Genet 1996;13:472-6.

1 Haines JL, Ter-Minassian M, Bazyk A, et al. A complete genomic screen for multiple sclerosis underscores a role for the major histocompatibility complex. Nature Genetics 1996;13:469-71.

12 Kuokkanen S, Gschwend M, Rioux JD, et al. Genomewide scan of multiple sclerosis in Finnish multiplex families. Am f Hum Genet 1997;61:1379-87.

13 Chataway J, Feakes R, Coraddu F, et al. The genetics of multiple sclerosis: principles, background and updated results of the United Kingdom systematic genome screen. results of the United Kingdi
Brain 1998;121:1869-87.

14 Coraddu F, Sawcer S, Feakes R, et al. HLA typing in the United Kingdom multiple sclerosis genome screen. Neurogenetics 1998;2:24-33.

15 Robertson NP, Clayton D, Fraser MA, et al. Clinical concordance in sibling pairs with multiple sclerosis. Neurology 1996;47:347-52.

16 Poser CM, Paty DW, Scheinberg L, et al. New diagnostic criteria for multiple sclerosis: guidelines for research protocols. Ann Neurol 1983;13:227-31.

17 Chataway J, Sawcer S, Coraddu F, et al. Evidence that allelic variants of the spinocerebellar ataxia type 2 gene influence susceptibility to multiple sclerosis. Neurogenetics 1999;2: 91-6.

18 Confraveux C, Compston DHR, Hommes OR, et al. EDMUS, a European database for multiple sclerosis. $f$ Neurol Neurosurg Psychiatry 1992;55:671-6.

19 Kurtzke JF. Rating neurological impairment in multiple sclerosis: an expanded disability scale status. Neurology 1983;33:1444-52.

20 Mumford CJ, Compston A. Problems with rating scales for multiple sclerosis: a novel approach: the CAMBS score. $\mathcal{f}$ Neurol 1993;240:209-15. 
21 Fleiss JL. Statistical methods for rates and proportions. New York: Wiley, 1981

22 Efron B, Tibshirani RJ. An introduction to the bootstrap. London: Chapman and Hall, 1993.

23 Mander AP, Chataway J, Clayton DG, et al. Estimation of agreement in the presence of confounders. Annals of Human Genetics (submitted)

24 Curtius F, Speer H. Multiple Sklerose und Erbanlagen II Mittelung. Zeitschrift für die gesamte Neurologie und Psychiatrie 1937;160:226-45.

25 Roberts DF, Roberts MJ, Poskanzer DC. Genetic analysis of multiple sclerosis in Orkney. $\mathcal{F}$ Epidemiol Community Health 1979;33:229-35.

26 Bulman DE, Sadovnick AD, Ebers GC. Age of onset in sibling pairs concordant for multiple sclerosis. Brain 1991; 114: $937-50$
27 Doolittle TH, Myers RH, Lehrich JR, et al. Multiple sclerosis sibling pairs: clustered onset and familial predisposition. Neurology 1990;40:1546-52.

28 French Research Group for Multiple Sclerosis. Familial factors influence disability in MS multiplex families. Neurology 1999;52:1632-6.

29 Schapira K, Poskanzer DC, Miller H. Familial and conjugal multiple sclerosis. Brain 1963;86:315-32.

30 Weinshenker B, Armstrong H, Bulman D. A comparison of familial and sporadic MS. Can F Neurol Sci 1986;13:168.

31 Koch-Henrikson N. An epidemiological study of multiple sclerosis. Acta Neurologica Scandinavica 1989;80(suppl):1123.

32 American Multiple Sclerosis Group. Clinical demographics of multiplex families with multiple sclerosis. Ann Neurol 1998;43:530-4.

\section{NEUROLOGICAL STAMP}

\section{Phineas Gage and the science of brain localisation}

An injury with an improbable outcome that occurred to a to a railway foreman on 13 September 1848 had an influence on the science of localisation of brain function. Phineas Gage was the foreman of a railway construction crew working just outside Cavendish, Vermont. He was the company's most capable foreman with a well balanced mind and shrewd business sense.

Gage was tamping an explosion charge. A tamping iron is a crowbar-like tool used to compact an explosive charge into the bottom of a borehole. The tamping iron used by Gage was 43 inches in length, 1.25 inches in diameter at one end, tapering over a distance of 12 inches to a diameter of 0.25 inches at the other end, and weighing about 13 pounds. Tamping involves packing of a charge into as small a space as possible at the point chosen for the explosion. An accidental explosion of the charge Phineas Gage had just set blew his tamping iron out of the borehole and through the left side of his skull. It entered a point first under his left cheek bone, exiting through the top of his head and landing some 25 to 30 yards away Gage was knocked over but may not have lost consciousness. Most of the left frontal lobe was destroyed.

The railway physician, Dr John Harlow, wrote to the Boston Medical and Surgical fournal (volume 29, Wednesday 13 December 1848)

"The accident occurred on 13 September last at 4 o'clock pm. The tamping iron had taken a direction upwards and backwards towards the median line, penetrating the integuments, the masseter and temporal muscles, passing under the zygomatic arch and (probably) fracturing the temporal portion of the sphenoid bone, and the floor of the orbit of the left eye, entering the cranium, passing through the anterior left lobe of the cerebrum and making its exit along the median line, at the junction of the coronal and sagittal sutures, lacerating the longitudinal sinus, fracturing the parietal and frontal bones extensively, breaking up

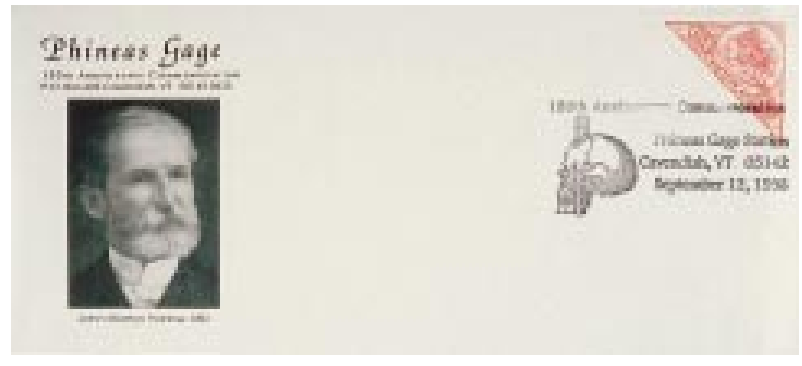

considerable portions of brain, and protruding the globe of the left eye from its socket, by nearly one half of its diameter...I am informed that the patient was thrown on his back and gave a few convulsive motions of the extremities but spoke in a few minutes ... I did not arrive at the scene of the accident till 6 o clock pm ... assisted by my friend Dr Williams ... I passed in the index finger its whole length without the least resistance in the direction of the wound in the cheek, which received the other finger in a like manner A portion of the anterior superior angle of each parietal lobe, and a semicircular piece of frontal bone, were fractured, leaving a circular opening of about 3 inches in diameter ... the iron which was found some rods distance, smeared with brain ..."

Postinjury deterioration occurred with restlessness, deliriousness, and infection. Despite his horrific injury Phineas recovered. He could walk, speak, and had normal awareness. Despite exemplary work before his accident, his employer would not return him to his former position. $\mathrm{He}$ had become fitful, irreverent, grossly profane, and showed little deference for other workers. Impatient and obstinate yet capricious and vacillating, he was unable to proceed with any plans. According to friends he was "no longer Gage". He performed various odd jobs including caring for horses and often driving a heavily laden coach drawn by six horses.

Seizures started in February 1860. Gage died on 21 May 1860, 4 months after his first seizure after the injury. No postmortem studies were made. In 1867 his body was exhumed from San Francisco's Lone Mountain Cemetery. The skull and the famous tamping iron were delivered by his brother in law to Dr Harlow. These were donated to the Warren Museum at Harvard University School of Medicine.

In 1994 the case was revisited. A group of researchers who examined the skull with modern computer reconstruction techniques attempted to deduce the most likely trajectory of the tamping rod. They found that the areas of the neocortex damaged corresponded to the areas damaged in the frontal lobe syndrome.

On Sunday 13 September 1998 a cast bronze plaque commemorating Phineas Gage's injury was unveiled at Cavendish Town Green. The postmark, like the plaque, commemorates the 150th anniversary of the event. The first day cover also shows Dr John Martin Harlow

L F HAAS

I thank Dr T Hines for bringing this extraordinary event and the philatelic commemoration to my attention. 